González-Guerrero, O., Cruañas Cruells, G., Ninyerola Casals, M. (2017): “Análisis de la dinámica espacio-temporal (1948-2003) del límite altitudinal del bosque (tree line) en Andorra mediante fotografia aérea”, GeoFocus (Artículos), $n^{\circ}$ 19, p. 3-25. ISSN: 1578-5157 http://dx.doi.org/10.21138/GF.458

\title{
ANÁLISIS DE LA DINÁMICA ESPACIO-TEMPORAL (1948-2003) DEL LÍMITE ALTITUDINAL DEL BOSQUE (TREE LINE) EN ANDORRA MEDIANTE FOTOGRAFÍA AÉREA
}

\author{
OSCAR GONZÁLEZ-GUERRERO ${ }^{1}$, GUILLEM CRUAÑAS CRUELLS ${ }^{1}$, MIQUEL \\ NINYEROLA CASALS ${ }^{2}$ \\ ${ }^{1}$ Universitat Autònoma de Barcelona. \\ 08193 Bellaterra, España. \\ ${ }^{2}$ Grumets research group. Dep. Biologia Animal, Vegetal i Ecologia. Edifici C. Universitat \\ Autònoma de Barcelona. 08193 Bellaterra, España. \\ oscar.gonzalez.guerrero@uab.cat
}

\section{RESUMEN}

Los cambios en la distribución espacio-temporal de los ecosistemas arbóreos son un reflejo de las perturbaciones de origen antrópico así como de los cambios provocados por la dinámica del clima. En este sentido, resulta de especial interés el estudio de los movimientos en la tree line, definida como área geográfica donde las condiciones ambientales ya no permiten que los árboles se desarrollen en colectividad. En este contexto, el presente estudio se centra en tres zonas piloto de los Pirineos centrales (1.800-2.600 m s.n.m.), y se ha realizado mediante fotointerpretación de imágenes aéreas tomadas en 1948, 1972, 1995 y 2003. El trabajo constata, mediante técnicas SIG, que en estas zonas, cercanas a la tree line, se produce un aumento de la superficie ocupada por bosque (que oscila entre 0,46 y 0,95 ha por año) así como una densificación de los ecosistemas arbóreos pre-existentes. Además muestra las variaciones posicionales de la tree line así como los desplazamientos lineales (entre 26 y $94 \mathrm{~m}$ ) en la posición altitudinal de los árboles pioneros a lo largo de los 55 años de estudio.

Palabras clave: límite altitudinal del bosque, Andorra, georeferenciación, fotointerpretación.

SPATIO-TEMPORAL ANALYSIS (1948-2003) OF THE DYNAMICS OF THE FOREST ALTITUDINAL LIMIT (TREE LINE) IN ANDORRA USING AERIALPHOTOGRAPHY

\section{ABSTRACT}

Changes in the spatio-temporal distribution of arboreal ecosystems are a reflection of anthropogenic disturbances as well as the changes caused by climate dynamics. In this regard, it is 
González-Guerrero, O., Cruañas Cruells, G., Ninyerola Casals, M. (2017): “Análisis de la dinámica espacio-temporal (1948-2003) del límite altitudinal del bosque (tree line) en Andorra mediante fotografia aérea”, GeoFocus (Artículos), $n^{\circ}$ 19, p. 3-25. ISSN: 1578-5157 http://dx.doi.org/10.21138/GF.458

of special interest to study the movements in the tree line, defined as a geographical area where environmental conditions no longer allow trees to develop in community. In this context, this study focuses on three pilot areas of the central Pyrenees (1800-2600 m a.s.1.), and it has been performed by photo interpretation of aerial images taken in 1948, 1972, 1995 and 2003. The work shows, using GIS techniques, that in these areas, close to the tree line, an increase in the area covered by forest (ranging between 0.46 and 0.95 ha per year) and a densification of pre-existing arboreal ecosystems occurs. It also shows the positional variations of the tree line as well as linear displacements (between 26 and $94 \mathrm{~m}$ ) in the altitudinal position of the pioneer's trees along the 55 years of study

Keywords: Forest altitudinal limit, Andorra, georeferencing, photointerpretation.

\section{Introducción y obje tivos}

El límite de la tree line delimita el área geográfica donde las condiciones ambientales (condiciones de frio extremo, presencia de permafrost, suelos poco desarrollados, viento intenso, ausencia de cobertura arbustiva, presencia de especies herbáceas resistentes a la colonización de especies leñosas, presencia de herbivoría, procesos estocásticos como aludes, etc) ya no permiten que los árboles se desarrollen en colectividad (Körner, 1998). La dinámica de la tree line permite estudiar la influencia de estas condiciones ambientales al ser un ambiente donde los vegetales se encuentran cerca de su límite de tolerancia ecofisiológica y, por tanto, dichas interacciones se traducen en cambios más evidentes que en otras zonas donde la idone idad del bosque es mayor. Por todo ello, la tree line es utilizada con frecuencia como uno de los principales indicadores del cambio climático (Noble, 1993; Kullman, 1998; Camarero et al., 2015) aunque también sea un refle jo de la intensidad de la actividad humana, repercutiendo ambos factores en cambios en la distribución altitudinal del bosque. Así pues, los cambios en la distribución espacio-temporal de los ecosistemas arbóreos son un reflejo de las perturbaciones de origen antrópico (deforestación generada por la tala y la quema con finalidades agrícolas, ganaderas, urbanísticas o lúdicas) así como de los cambios provocados por la dinámica del clima (cubierta nival, humedad del suelo, duración del periodo de crecimiento, elevado régimen de incendios, cambios en la idoneidad de las especies, etc).

Muchos estudios proponen la temperatura como el principal factor de control de la dinámica de la tree line (Kullman, 2001; Grace et al., 2002; Körner, 2007; Camarero et al., 2015; MoruetaHolme et al., 2015), incluyendo la precipitación en el caso de Elliot (2012). Además en el caso de Walther et al. (2005) se detecta una cierta aceleración del desplazamiento altitudinal del bosque durante las últimas décadas.

Ahora bien, la influencia antrópica es también muy evidente. Incluso en los ambientes de alta montaña, donde la actividad humana durante las últimas décadas ha sido menor que en otros ecosistemas, han aflorado evidencias que la presión ejercida por los seres humanos viene desde antiguo y ha sido más intensa de lo que se pensaba (Cunill et al., 2012; Wick et al. 2003; B larquez et al. 2009; Valsecchi \& Tinner, 2010; Schworer et al., 2014). Así pues, el este impacto ha causado una disminución de la tree line a lo largo de los últimos milenios de hasta unos 100-500 m (Tinner \& Theurillat, 2003) y Cunill et al. (2012) detectan cambios de hasta $400 \mathrm{~m}$ causados seguramente por fuegos de naturaleza antrópica. Evidencias de la influencia de los cambios de usos más recientes 
González-Guerrero, O., Cruañas Cruells, G., Ninyerola Casals, M. (2017): “Análisis de la dinámica espacio-temporal (1948-2003) del límite altitudinal del bosque (tree line) en Andorra mediante fotografia aérea”, GeoFocus (Artículos), $n^{\circ}$ 19, p. 3-25. ISSN: 1578-5157 http://dx.doi.org/10.21138/GF.458

los encontramos en Améztegui et al. (2010 y 2016) que relacionan cambios en la tree line en áreas con importantes modificaciones de los usos del suelo a lo largo del siglo pasado.

Debido a la estrecha relación de estos factores en la mayoría de las situaciones resulta muy difícil diferenciar entre los efectos del cambio de los usos del suelo y los efectos naturales de la variabilidad climática (Didier, 2001; Gehrig-Fasel et al. 2007) aunque, probablemente, actúan ambos en la misma dirección (Gartzia et al., 2014).

Sin embargo existe un elevado consenso en que durante las últimas décadas se ha observado que la tree line ha incrementado su límite altitudinal aunque la magnitud varíe según la zona estudiada (Harsch et al., 2009; Rey et al., 2013; Schwörer et al., 2014; Améztegui et al., 2016) y los factores topoclimáticos (por. ej., zonas resguardadas de los vientos o con cubierta nival) tal y como apunta Kullman, L. (2001). De hecho, los cambios no solo afectan a la altitud donde encontramos los últimos árboles del bosque, sino que también se pueden detectar otros cambios como el grado de desarrollo de los árboles (p. ej, incremento del diámetro basal), el aumento de densidad de árboles en las zonas cercanas a la tree line (Danby \& Hik, 2007) o una intensa regeneración del bosque (Camarero et al., 2015). Además, la composic ión de la comunidad alpina ha cambiado (Keller et al., 2000) y las especies de la tree line han invadido la zona alpina o incrementado las tasas de crecimiento durante las últimas décadas (Gindl, 1999; Paulsen et al., 2000; Motta \& Nola, 2001). En todo caso, la expansión de los bosques durante este período ha tenido lugar en condiciones extremadamente favorables debido, tanto al calentamiento global como a un descenso de las actividades humanas (Motta et al., 2006; Carlson et al., 2014). La dinámica de las especies formadoras de la tree line ha dado lugar a estructuras diferenciadas según los procesos ambientales que hayan operado en cada lugar. Por encima de la timber line (zona donde el bosque se halla bien establecido), podemos encontrar que la delimitación de la tree line puede ser difusa (incluyendo las poblaciones arbóreas y arbustivas rastreras o krummholz; Harsch et al., 2009.) a lo largo del gradiente altitudinal o bien abrupta.

El interés por realizar un estudio regional que permita determinar las contribuciones de los factores antrópicos y climáticos que han operado sobre nuestros sistemas arbóreos, nos ha levado a realizar este trabajo previo que tiene por objetivo constatar el movimiento y la estructura de la tree line mediante fotointerpretación (Carlson et al., 2014; Jacob et al. 2015; Stueve et al. 2011; Danby \& Hik, 2007). Para el estudio de la dinámica de la tree line existen diferentes aproximaciones. Las técnicas de estudio in-situ (pedoantracología, paleopalinología, dendrología, inventarios ecológicos de campo) permiten analizar o diseñar experimentos para determinar la causalidad, pero son técnicas generalmente de abasto muy local. En cambio, las técnicas basadas en sensores ex-situ (fotointerpretación, teledetección) permiten potencialmente disponer de visiones globales para amplios territorios.

Aunque existen estudios realizados con información satelital (Gartzia et al., 2014; Zhang et al. 2009), en este estudio preliminar pretendemos precisar qué grado de detectabilidad de estos cambios se puede determinar mediante fotointerpretación con la mirada puesta en relacionar, posteriormente, la información fotointerpretada con la proveniente de teledetección (normalmente con una resolución espacial mucho menor). Esto permitirá realizar un análisis más robusto y completo espacio-temporalmente para un ámbito extenso como es la España peninsular con menos capacidad de discriminar entre las tree line difusas y abruptas. Concretamente el presente trabajo 
González-Guerrero, O., Cruañas Cruells, G., Ninyerola Casals, M. (2017): “Análisis de la dinámica espacio-temporal (1948-2003) del límite altitudinal del bosque (tree line) en Andorra mediante fotografia aérea”, GeoFocus (Artículos), $n^{\circ}$ 19, p. 3-25. ISSN: 1578-5157 http://dx.doi.org/10.21138/GF.458

pretende cuantificar los cambios que ha experimentado la tree line en los Pirineos centrales (Andorra) durante un periodo de 55 años (1948-2003), sin pretender determinar la causalidad del cambio, mediante fotointerpretación y un posterior anális is espacial mediante herramientas SIG.

\section{2. Área de estudio}

Aplicando técnicas SIG (ver apartado 3.2.) se han seleccionado tres zonas de muestreo en función de diferentes parámetros ambientales, con la finalidad de observar distintas dinámicas de la tree line. Todas ellas se hallan situadas en el territorio de Andorra. Este país, ubicado en la vertiente peninsular de los Pirineos centrales, tiene una extensión de $468 \mathrm{~km}^{2}$ de enorme complejidad orográfica (el $75 \%$ del territorio se encuentra por encima de los $1.800 \mathrm{~m}$ de altitud, siendo el punto más alto el pico de Coma Pedrosa, a 2.942 m). Exceptuando el piso alpino, gran parte de esta región es forestal (pinares de pino negro, pinares de pino albar, abetales, robledales húmedos y encinares) y su clima es de alta montaña con una fuerte influencia mediterránea.

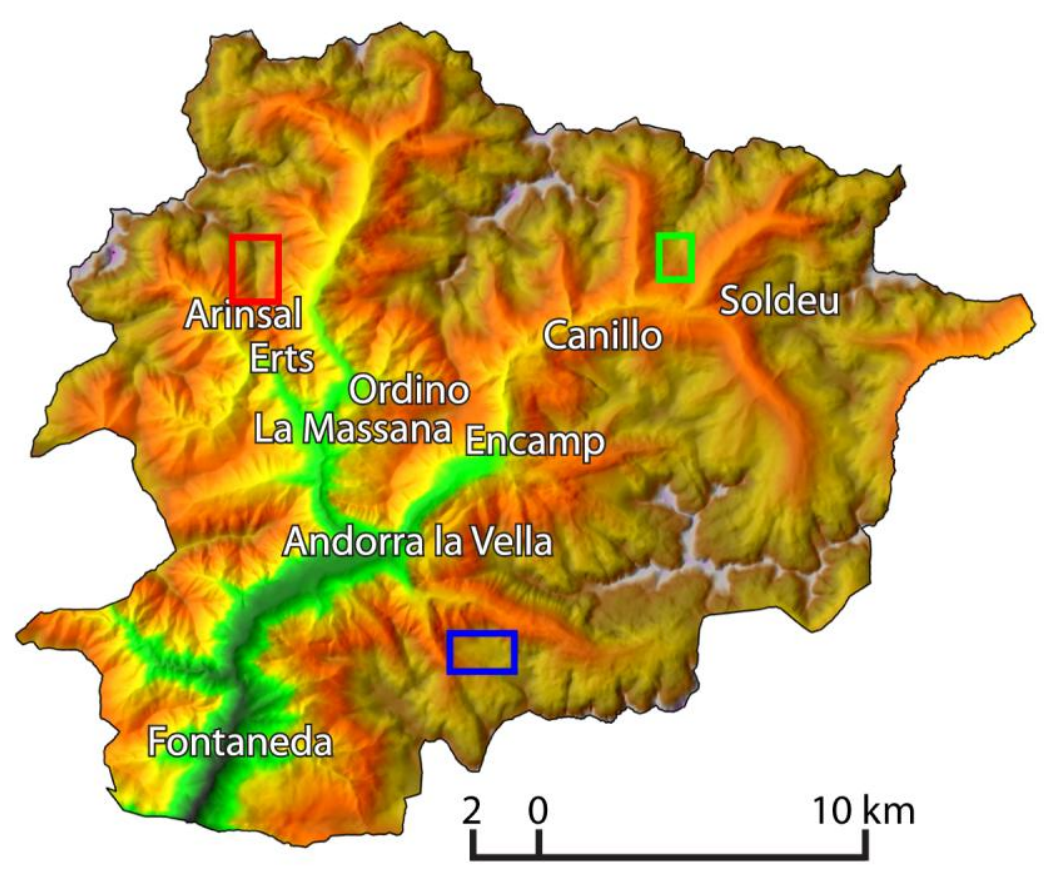

SRH: proyección Cónica Conforme de Lambert para la zona III (Sur de Francia y Andorra) con Datum NTF

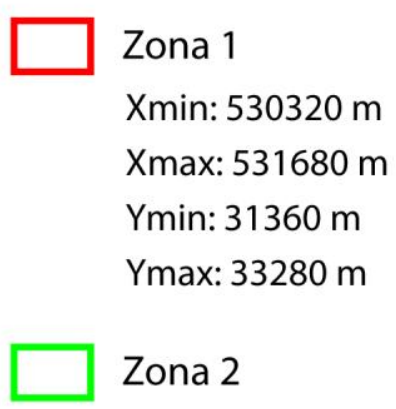

Xmin: $543360 \mathrm{~m}$

Xmax: $544320 \mathrm{~m}$

Ymin: $32000 \mathrm{~m}$

Ymax: $33360 \mathrm{~m}$

Zona 3

Xmin: $536960 \mathrm{~m}$

Xmax: $538880 \mathrm{~m}$

Ymin: $20000 \mathrm{~m}$

Ymax: $21200 \mathrm{~m}$

Figura 1. Mapa de situación de Andorra y las zonas de estudio se leccionadas.

En las zonas limítrofes entre el piso subalpino y el piso alpino, la especie arbórea dominante es el pino negro (Pinus mugo subsp. uncinata Ramond ex DC), situado entre los $1.300 \mathrm{~m}$ y los $2.500 \mathrm{~m}$ de altitud. 
González-Guerrero, O., Cruañas Cruells, G., Ninyerola Casals, M. (2017): “Análisis de la dinámica espacio-temporal (1948-2003) del límite altitudinal del bosque (tree line) en Andorra mediante fotografia aérea”, GeoFocus (Artículos), $n^{\circ}$ 19, p. 3-25. ISSN: 1578-5157 http://dx.doi.org/10.21138/GF.458

En la figura 1 podemos ver las tres zonas seleccionadas para el estudio. La zona 1, situada entre la parroquia de Ordino y de la Massana, está comprendida entre los $1.838 \mathrm{~m}$ y los $2.564 \mathrm{~m}$ de altitud con una pendiente media del $56 \%$ y orientación sur-este; La zona 2 corresponde a la parroquia de Canillo entre los $1.991 \mathrm{~m}$ y $\operatorname{los} 2.447 \mathrm{~m}$ de altitud con una orientación sur y una pendiente media del $37 \%$; finalmente, la zona 3 pertenece a la parroquia de Escaldes-Engordany, entre los $2.026 \mathrm{~m}$ y los $2.450 \mathrm{~m}$ de altitud con orientación sur-oeste y una pendiente media del $34 \%$. Las zonas seleccionadas tienen una extensión de $244,8,122,4$ y 216 ha respectivamente y, en conjunto, comprenden una superficie total de 583,2 ha. No se han ubicado zonas de orientación norte debido a la disponibilidad de fotografías de calidad y el hecho de que según Paulsen \& Körner (2001) las orientaciones no juegan un papel importante en el desarrollo de la tree line.

\section{Mate riales y métodos}

\subsection{Las fotografías aéreas}

Para poder cuantificar la variación de la tree line en Andorra se han utilizado una serie de imágenes proporcionadas por el Centre d 'Estudis de la Neu i la Muntanya d'Andorra (CENMA) de diferentes años. Las imágenes de los vuelos fotográmetricos proporcionadas por el CENMA son de los años 1948, 1972, 1995 y 2003. En el caso de las imágenes de 1948 fueron obtenidas por el Institut Géographique National (IGN), las imágenes de 1972, 1995 y 2003 pertenecen al Ministeri d'Ordenament Territorial (MOT) del gobierno de Andorra. Todas las imágenes se encuentran en formato JPEG y van acompañadas de los metadatos esenciales para su correcta georeferenciación.

El vuelo del año 1948 fue realizado por el ejército francés a finales de la Segunda Guerra Mundial a una escala 1:25.000. Consta de 6 pasadas y 137 fotogramas de 11,5 $\mathrm{cm} \mathrm{x} 16,5 \mathrm{~cm}$ en pancromático y $1 \mathrm{~m}$ de resolución. Las imágenes originales son en formato analógico y se encuentran deterioradas por el paso del tiempo. Para su uso en este trabajo ha sido necesario su escaneo y posterior georeferenciación. Este proceso de georeferenciación ha implicado el uso del Modelo Digital de Elevaciones (MDE) de $5 \mathrm{~m}$ de resolución del CENMA. En cuanto a los datos del resto de vuelos proporcionados por el CENMA, las imágenes se encuentran en formato digital y ya georeferenciadas. La tabla 1 resume las características del conjunto de imágenes.

Tabla 1. Información de las imágenes fotogramétricas usadas en su formato original.

\begin{tabular}{|c|c|c|c|c|}
\hline & 1948 & 1972 & 1995 & 2003 \\
\hline Número de imáge nes & 137 & 71 & 74 & 90 \\
\hline BN/RGB & $\overline{\mathrm{BN}}$ & $\overline{\mathrm{BN}}$ & $\overline{\mathrm{RGB}}$ & RGB \\
\hline Resolución & $\sim 1 \mathrm{~m}$ & $0,5 \mathrm{~m}$ & $1 \mathrm{~m}$ & $0,5 \mathrm{~m}$ \\
\hline RMS & \multirow{2}{*}{$\begin{array}{l}\text { No existe } \\
\text { corrección } \\
\text { geométrica }\end{array}$} & $3,3284 \mathrm{~m}$ & $1,5407 \mathrm{~m}$ & $0,5525 \mathrm{~m}$ \\
\hline Proyección & & \multicolumn{3}{|c|}{ Lambert Conformal Conic Zone III NTF } \\
\hline
\end{tabular}

Así pues, para poder cubrir las tres zonas de estudio, en total ha sido necesario georeferenciar 8 imágenes de 1948 utilizando como imágenes de referencia las ya georeferenciadas del vuelo de 2003 (por ser las imágenes con menor error planimétrico) y de 1972 (por ser los datos más cercanos en el tiempo). Cabe destacar que el uso de las imágenes de 1972 ha conllevado ciertas 
González-Guerrero, O., Cruañas Cruells, G., Ninyerola Casals, M. (2017): “Análisis de la dinámica espacio-temporal (1948-2003) del límite altitudinal del bosque (tree line) en Andorra mediante fotografia aérea”, GeoFocus (Artículos), $n^{\circ}$ 19, p. 3-25. ISSN: 1578-5157 http://dx.doi.org/10.21138/GF.458

complicaciones debido a su calidad, composición y georeferenciación. Tal y como muestran los ejemplos de la figura 2, encontramos zonas borrosas en lugares de relieve abrupto (probablemente debidas al ángulo de captación de la imagen y a deficiencias en el modelo digital del terreno utilizado en la corrección) así como problemas de encaje entre fotogramas que crean discontinuidades en el territorio fotografiado.
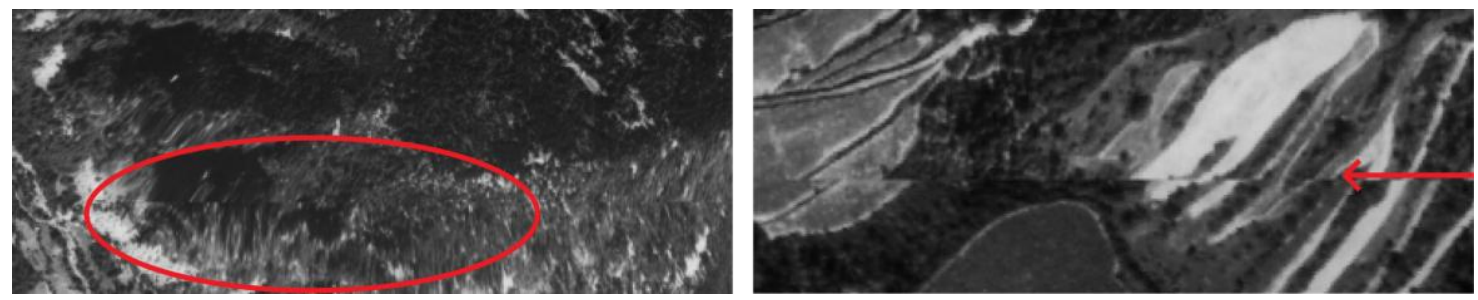

Figura 2. Defectos en las imáge nes del vuelo de 1972. Izquierda, zonas borrosas debidas, probablemente, al ángulo de captación y al relieve. De recha, zonas de desencaje entre elementos continuos.

Para la georeferenciación de estas imágenes se ha seleccionado un mínimo de 20 puntos inequívocos, de los cuales 16 se utilizan como puntos de ajuste y el resto como puntos de test para determinar el error del modelo, obteniendo los valores de RMSE que se muestran en la tabla 2. Teniendo en cuenta que el mayor error obtenido es de 3,789 m, podemos afirmar que el $90 \%$ de los píxeles tienen un error inferior a los $5,75 \mathrm{~m}$.

Tabla 2. Errores estimados en la geogrefe re nciación de las imágenes de 1948.

\begin{tabular}{|r|c|r|}
\hline ID imagen & RMS & Error 90 \% puntos \\
\hline 155 & $3,280 \mathrm{~m}$ & $4,978 \mathrm{~m}$ \\
\hline 78 & $2,221 \mathrm{~m}$ & $3,370 \mathrm{~m}$ \\
\hline 76 & $3,399 \mathrm{~m}$ & $5,158 \mathrm{~m}$ \\
\hline 75 & $2,589 \mathrm{~m}$ & $3,928 \mathrm{~m}$ \\
\hline 68 & $3,789 \mathrm{~m}$ & $5,750 \mathrm{~m}$ \\
\hline 66 & $2,378 \mathrm{~m}$ & $3,609 \mathrm{~m}$ \\
\hline 37 & $3,134 \mathrm{~m}$ & $4,756 \mathrm{~m}$ \\
\hline
\end{tabular}

\subsection{Selección de las zonas de estudio}

Para seleccionar las tres zonas de estudio se han utilizado datos (continentalidad y radiación solar potencial) del Atlas Climático Digital de Andorra (http://www.opengis.uab.es/wms/ACDA) y también el Mapa de Hábitats y el Modelo Digital de Elevaciones (MDE) de la zona (proporcionados por el CENMA).

En primer lugar, en función de la continentalidad (influencia marítima) se ha segmentado el área de estudio en dos sectores, uno considerado con mayor influencia atlántica y el otro con mayor influencia mediterránea. Por otro lado, utilizando la información de radiación solar se han generado tres clases delimitadas a partir de la mediana (radiación inferior a la mediana menos la desviación estándar, mediana \pm desviación estándar y mediana más desviación estándar). Finalmente, 
González-Guerrero, O., Cruañas Cruells, G., Ninyerola Casals, M. (2017): “Análisis de la dinámica espacio-temporal (1948-2003) del límite altitudinal del bosque (tree line) en Andorra mediante fotografia aérea”, GeoFocus (Artículos), $n^{\circ}$ 19, p. 3-25. ISSN: 1578-5157 http://dx.doi.org/10.21138/GF.458

combinando radiación solar, continentalidad, distribución de los hábitats de pino negro y prados alpinos y la altitud (entre los $1.836 \mathrm{~m}$ y $2.564 \mathrm{~m}$, franja que comprende el límite entre el piso alpino y el subalpino), se han definido las tres zonas de estudio buscando un compromiso entre zonas homogéneas según estas condiciones y la disponibilidad de imágenes de 2003.

\subsection{Fotointerpretación}

Los cambios en la tree line no sólo se evidencian a través del desplazamiento altitudinal en que aparecen los árboles, sino que también pueden detectarse a través del grado de recubrimiento boscoso de las zonas cercanas y del crecimiento interno del propio bosque (Danby and Hik, 2007). Así pues, durante el proceso de fotointerpretación también se ha tenido en cuenta este factor, determinando la densidad arbórea en cada una de las áreas delimitadas por una cuadrícula regular. Debido a la resolución espacial y radiométrica, sobretodo de las imágenes más antiguas, se ha optado por fotointerpretar la tree line de forma difusa en su sentido más amplio. Es decir, incluyendo las poblaciones donde los árboles crecen en colectividad hasta la línea altimétrica determinada por los árboles y arbustos pioneros que de forma aislada intentan colonizar los prados alpinos (Körner, 1998). En este sentido, las formas rastreras del krummholz quedaran incluidas dentro de los límites de nuestra tree line difusa.

En este sentido, en un primer paso se ha creado una cuadrícula de $80 \mathrm{~m}$ x $80 \mathrm{~m}$ sobre cada una de las zonas de estudio. Este tamaño de malla se ha establecido de forma que el mayor error obtenido en la georeferenciación $(3,78 \mathrm{~m})$ represente un error inferior al $5 \%$ de la cuadrícula a fotointerpretar. Además, este tamaño es un consenso entre la superficie total a estudiar y las posibilidades reales de fotointerpretar su contenido. En el caso de querer usar una cuadrícula con un paso de malla cercano al error de georeferenciación, se generarían miles de celdas para cubrir todo el ámbito de estudio.

La adjudicación del grado de recubrimiento a cada uno de los cuadros delimitados por la malla regular se ha realizado según los criterios mostrados en la figura 3 estableciendo las siguientes clases: $0 \%, 10 \%, 20 \%, 30 \%, 40 \%$ y $50 \%$.

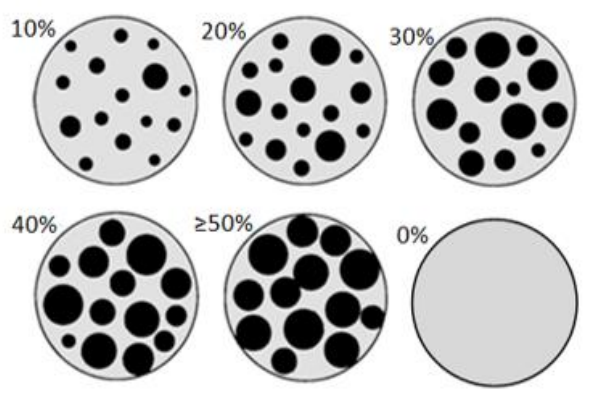

Figura 3. Esquema de la conside ración de los grados de recubrimiento arbóreo utilizados en la fotointerpretación. 
González-Guerrero, O., Cruañas Cruells, G., Ninyerola Casals, M. (2017): “Análisis de la dinámica espacio-temporal (1948-2003) del límite altitudinal del bosque (tree line) en Andorra mediante fotografia aérea”, GeoFocus (Artículos), $n^{\circ}$ 19, p. 3-25. ISSN: 1578-5157 http://dx.doi.org/10.21138/GF.458

Se ha definido como densidad arbórea mínima en el límite superior del bosque aquellas zonas con un recubrimiento igual o superior al $10 \%$. Densidades inferiores $(<10 \%)$ corresponderán a árboles pioneros, y se marcan con un $0 \%$ las zonas sin presencia de árboles. Así pues, se ha generado una nueva capa de información con el grado de recubrimiento entre el $10 \%$ y el $50 \%$ que nos permite trazar una primera aproximación a la tree line.

A continuación, se ha realizado una segunda fotointerpretación más detallada mediante el uso de una cuadrícula de $20 \mathrm{~m}$ x $20 \mathrm{~m}$ sobre la franja de $160 \mathrm{~m}$ a cada lado de la tree line anteriormente trazada. En este caso se han fotointerpretado únicamente tres categorías según el recubrimiento: $0 \%,<10 \% \mathrm{y} \geq 10 \%$. Este segundo paso ha permitido precisar el trazado de la tree line manteniendo la objetividad del método anterior.

Finalmente, se ha combinado la información generada en los pasos anteriores con el MDE para poder analizar los cambios a lo largo del tiempo y en función de la altitud. Los rangos altitudinales considerados para cada una de las tres zonas de estudio son los siguientes:

Tabla 3. Rangos altitudinales definidos para cada una de las zonas de estudio.

\begin{tabular}{|c|c|c|}
\hline Zona 1 & Zona 2 & Zona 3 \\
\hline $1.800-2.000 \mathrm{~m}$ & $1.990-2.105 \mathrm{~m}$ & $2.020-2.127 \mathrm{~m}$ \\
\hline $2.000-2.200 \mathrm{~m}$ & $2.105-2.220 \mathrm{~m}$ & $2.127-2.235 \mathrm{~m}$ \\
\hline $2.200-2.400 \mathrm{~m}$ & $2.220-2.335 \mathrm{~m}$ & $2.235-2.342 \mathrm{~m}$ \\
\hline $2.400-2.600 \mathrm{~m}$ & $2.335-2.450 \mathrm{~m}$ & $2.342-2.450 \mathrm{~m}$ \\
\hline
\end{tabular}

\section{Resultados y discusión}

\subsection{Recubrimiento y densidad arbórea}

Se han generado un total de 12 capas ráster (tres zonas de estudio para cada una de las 4 fechas disponibles) con información de recubrimiento arbóreo con un tamaño de píxel de $80 \mathrm{~m}$ x 80 $\mathrm{m}$ (véase figura 4). 
González-Guerrero, O., Cruañas Cruells, G., Ninyerola Casals, M. (2017): “Análisis de la dinámica espacio-temporal (1948-2003) del límite altitudinal del bosque (tree line) en Andorra mediante fotografia aérea”, GeoFocus (Artículos), $n^{\circ}$ 19, p. 3-25. ISSN: 1578-5157 http://dx.doi.org/10.21138/GF.458

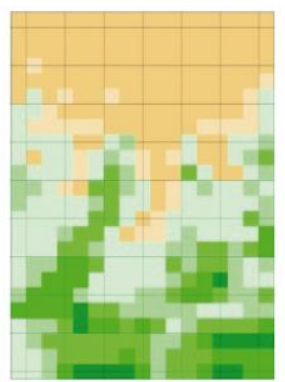

zona 1: 1948

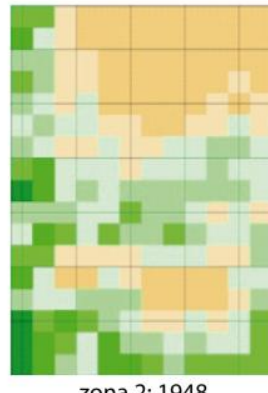

zona 2: 1948

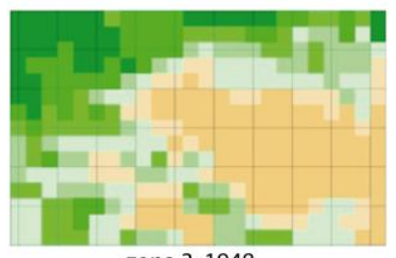

zona 3: 1948

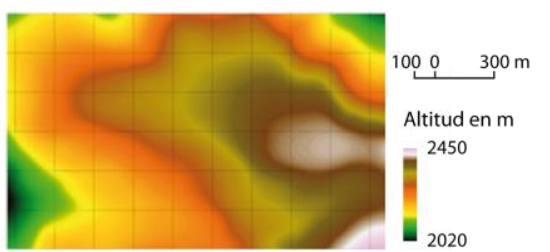

zona 1: 2003

zona 2: 2003
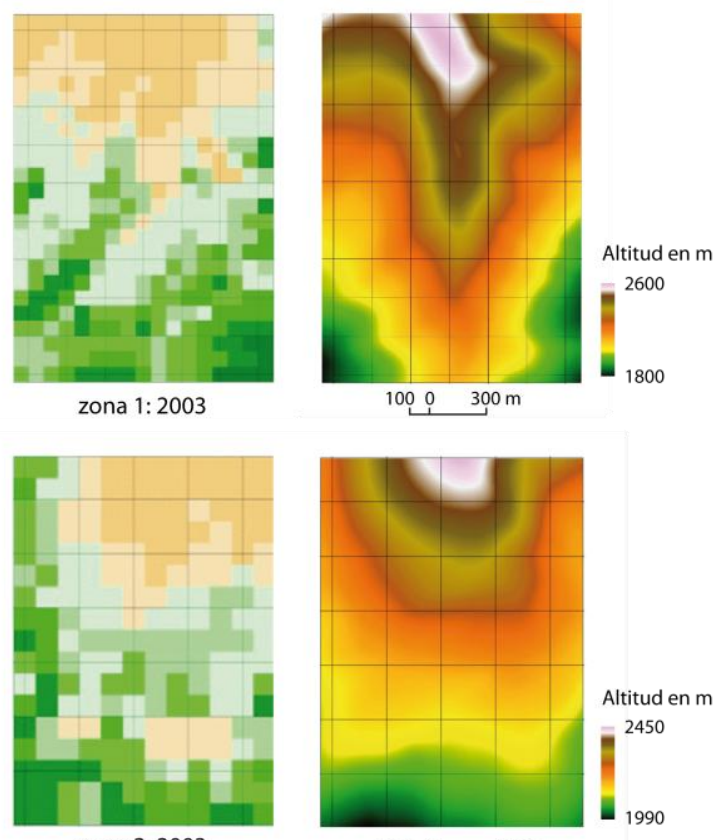

$100 \quad 0 \quad 300 \mathrm{~m}$

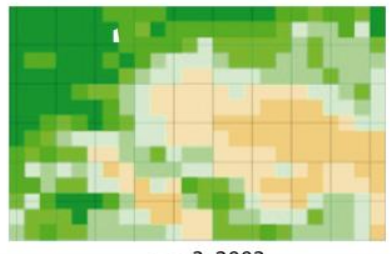

zona 3: 2003

$\%$ de recubrimiento arbóreo

\begin{tabular}{lll}
\hline & $\%$ \\
\hline & $20 \%$ & $\square 0 \%$
\end{tabular}

Pioneros $\square=30 \%$

$10 \%-40 \%$

Figura 4. Ejemplo del resultado de la fotointe rpretación según el porcentaje de recubrimiento arbóre o en las tres zonas de estudio para las imáge nes de 1948 y 2003.

La combinación de la nueva información de recubrimiento boscoso con el MDE permitió el cálculo del número de hectáreas ocupadas según el porcentaje de recubrimiento en distintos intervalos altitudinales. Esta información se detalla en las tablas del Apéndice 1.

En primer lugar, se observa cómo la superficie considerada como bosque (aquella con recubrimiento arbóreo igual o superior al 10\%) entre los años 1948 y 2003 tiene tendencia a aumentar en las tres zonas estudiadas (figura 5). Esta superficie presenta un incremento máximo del $23 \%$ (28,2 ha) en la zona 2, seguido por un $17 \%$ (38,4 ha) en la zona 3. En el caso de la zona 1, aunque existe también esta tendencia al alza, se ve truncada al analizar las imágenes de 2003. Así 
González-Guerrero, O., Cruañas Cruells, G., Ninyerola Casals, M. (2017): “Análisis de la dinámica espacio-temporal (1948-2003) del limite altitudinal del bosque (tree line) en Andorra mediante fotografia aérea”, GeoFocus (Articulos), $n^{\circ}$ 19, p. 3-25. ISSN: 1578-5157 http://dx.doi.org/10.21138/GF.458

pues, aunque el incremento de la superficie boscosa a lo largo de toda la serie es del $-3 \%$ (6,6 ha) en la zona 1, cabe destacar que hasta 1995 la superficie boscosa había aumentado un $4 \%$ (10,2 ha), pero entre 1995 y 2003 disminuyó un 7 \% (16,8 ha). Una observación detallada de las imágenes nos permite observar una deforestación lineal muy simétrica que podría ser debida a algún tipo de perturbación antrópica que justificaría este cambio en la tendencia.

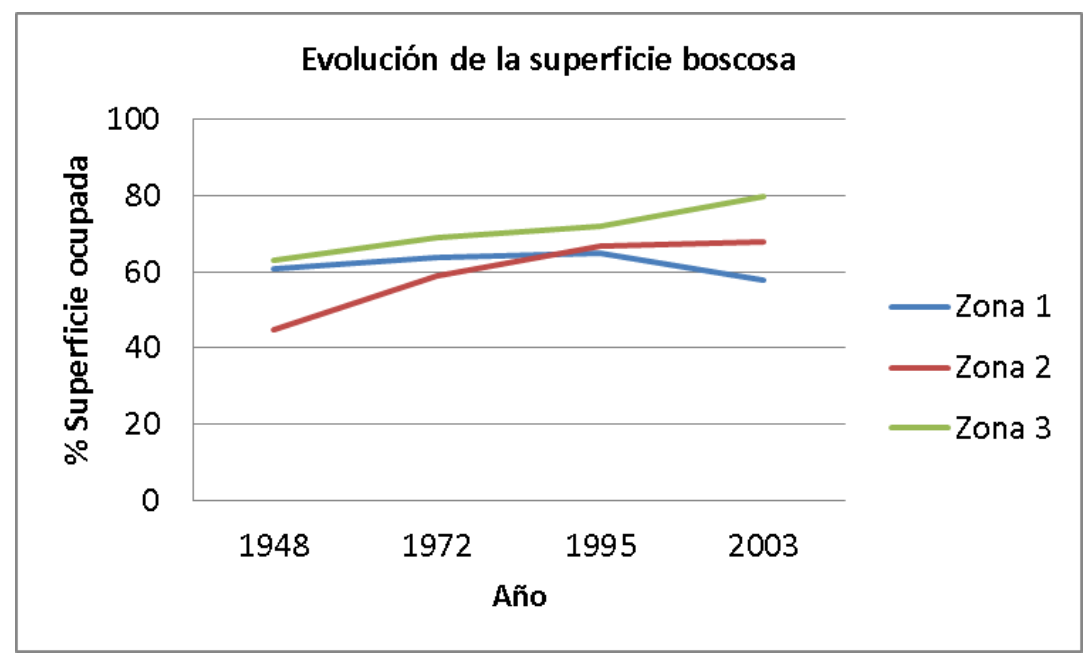

Figura 5.Evolución de la supe rficie boscosa (\% recubrimiento superior o igual al $10 \%)$ en las tres zonas de estudio a lo largo de la serie temporal.

Además, teniendo en cuenta los estratos altitudinales descritos en el apartado 3.3, se observa como este incremento de superficie boscosa se da principalmente en las zonas de mayor altitud y, por tanto, evidencia el avance de la tree line, ocupando espacios anteriormente sin o con un bajo recubrimiento arbóreo. El aumento del bosque en la zona 1 (+4 \% de superficie) se produce principalmente entre los $2.200 \mathrm{~m}$ y $2.400 \mathrm{~m}$ y que la perturbación anteriormente mencionada afecta, básicamente, a los árboles situados entre los $2.000 \mathrm{~m}$ y los $2.200 \mathrm{~m}$ (-7\% de superficie), aunque también a zonas más bajas. En cuanto a la zona 2, el mayor aumento de la superficie boscosa $(+16 \%$ de superficie) se produce entre los $2.105 \mathrm{~m}$ y $2.220 \mathrm{~m}$, seguido de un incremento del $6 \%$ de superficie boscosa entre los $2.220 \mathrm{~m}$ y los $2.335 \mathrm{~m}$. Finalmente, en la zona 3, el mayor incremento se produce entre los $2.235 \mathrm{~m}$ y los $2.342 \mathrm{~m}$ (+9 \% de superficie), muy parecido al incremento del $8 \%$ de superficie boscosa que se produce entre los $2.342 \mathrm{~m}$ y $2.450 \mathrm{~m}$ (véase figura 6 ). 
González-Guerrero, O., Cruañas Cruells, G., Ninyerola Casals, M. (2017): “Análisis de la dinámica espacio-temporal (1948-2003) del limite altitudinal del bosque (tree line) en Andorra mediante fotografia aérea”, GeoFocus (Articulos), $n^{\circ}$ 19, p. 3-25. ISSN: 1578-5157 http://dx.doi.org/10.21138/GF.458

Evolución de la superficie boscosa en los distintos estratos altitudinales

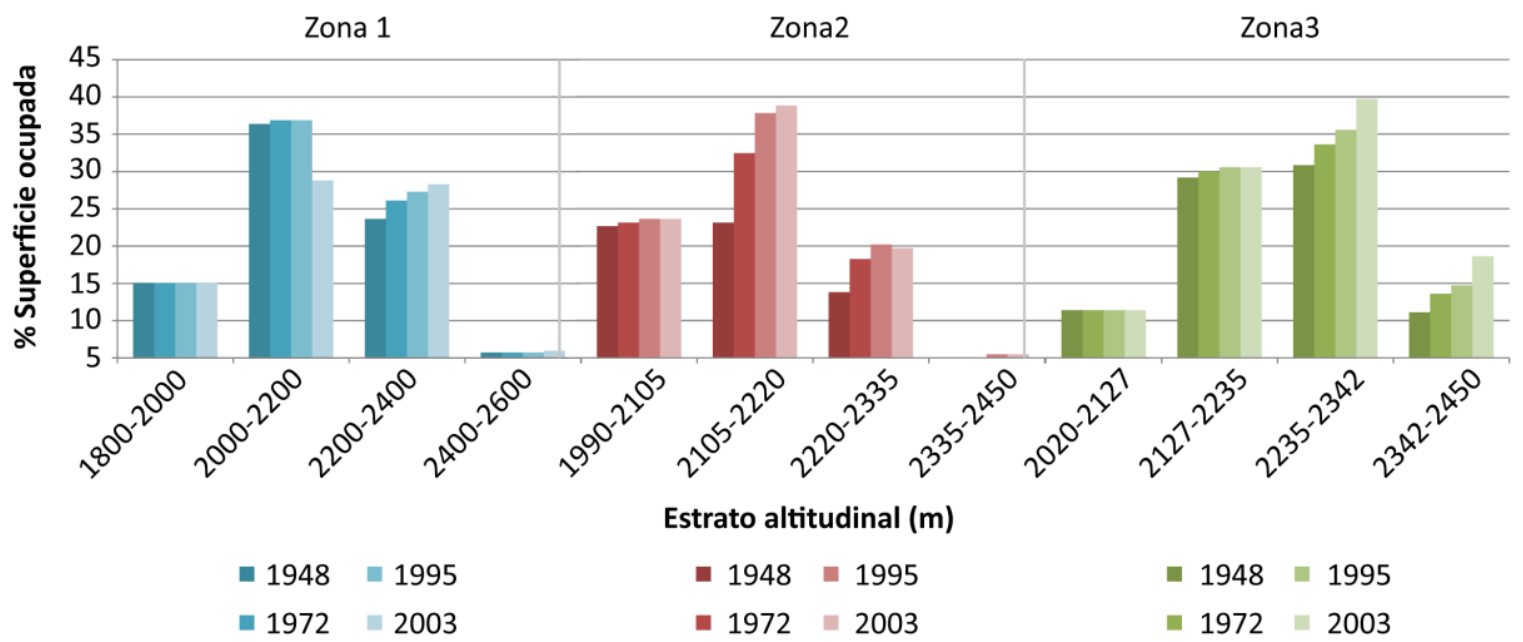

Figura 6. Evolución de la supe rficie boscosa (\% recubrimiento superior o igual al 10\%) en las tres zonas de estudio según el estrato altitudinal a lo largo de la serie temporal.

Por otra parte, si definimos las categorías bosque claro y bosque denso como aquellas con un recubrimiento inferior o igual al $20 \%$ o superior o igual al $30 \%$ respectivamente, se observa como la superficie de bosque denso aumenta en las tres zonas de estudio (figura 7). Esto es especialmente interesante en aquellos estratos altitudina les en que la superfic ie de suelo colonizable es nula en todas las fechas analizadas (las zonas a menor altitud), ya que se comprueba como en situaciones donde los arboles no pueden colonizar nuevos espacios, el bosque tiende a densificarse (figura 8).

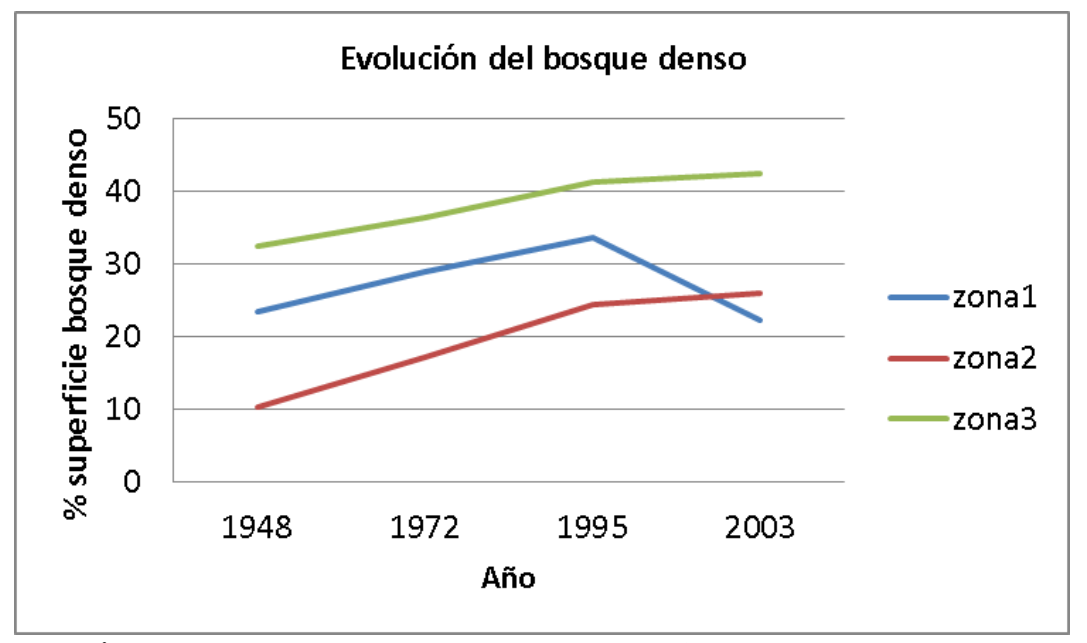

Figura 7. Evolución de la superficie de bosque denso (\% recubrimiento superior o igual al $30 \%$ ) en las tres zonas de estudio a lo largo de la serie temporal. 
González-Guerrero, O., Cruañas Cruells, G., Ninyerola Casals, M. (2017): “Análisis de la dinámica espacio-temporal (1948-2003) del limite altitudinal del bosque (tree line) en Andorra mediante fotografia aérea”, GeoFocus (Articulos), $n^{\circ}$ 19, p. 3-25. ISSN: 1578-5157 http://dx.doi.org/10.21138/GF.458

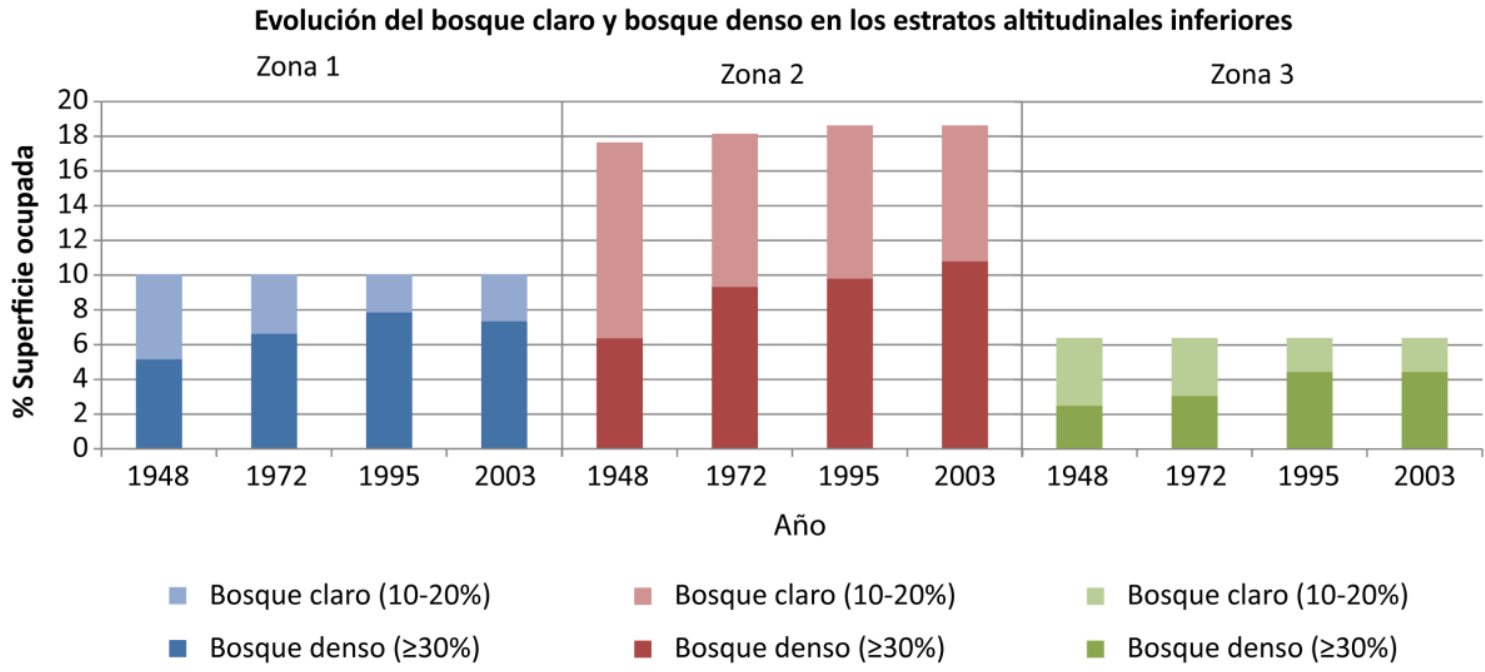

Figura 8. Evolución de la superficie de bosque claro y bosque denso en los estratos altitudinales inferiores de las tres zonas de estudio a lo largo de la serie temporal.

En segundo lugar, la presencia de árboles pioneros (correspondientes a aquellas zonas fotointerpretadas con un grado de recubrimiento arbóreo inferior al $10 \%$ ), tanto en la zona 1 como en la zona 3, tiende a aumentar. La presencia de árboles pioneros se da, principalmente, en los estratos altitudinales superiores. Así pues, en el caso de la zona 1 el aumento global es del $17 \%$ en superficie a lo largo de toda la serie, aunque debe tenerse en cuenta que la mayor parte de esta colonización se da entre los años 1995 y 2003 y en el estrato altitudinal coincidente con la perturbación ya descrita, con lo cual, podemos afirmar que en este caso no se trata de la colonización de nuevos espacios, sino de la reocupación de un terreno perdido. Si no tenemos en cuenta las imágenes de 2003, el aumento de superficie de los árboles pioneros en esta zona es del $6 \%$. En el caso de la zona 2, la tendencia global es negativa. La superficie ocupada por árboles pioneros disminuye un $2 \%$ a lo largo de la serie temporal. Esto se debe principalmente a que en las imágenes de 1948 encontramos una gran superficie (15,6 ha, el $13 \%$ de la superficie total estudiada) de árboles pioneros en los rangos altitudinales más bajos, probablemente debido a una perturbación anterior. Entre 1948 y 1972 esta superficie se densifica en gran parte. Así, si nos fijamos únicamente en la superficie ocupada por árboles pioneros a partir de los $2.220 \mathrm{~m}$ de altitud, vemos como la tendencia en la zona 3 también puede considerarse al alza. En este caso, la superficie aumenta un $5 \%$ (véase figura 9). 
González-Guerrero, O., Cruañas Cruells, G., Ninyerola Casals, M. (2017): “Análisis de la dinámica espacio-temporal (1948-2003) del limite altitudinal del bosque (tree line) en Andorra mediante fotografia aérea”, GeoFocus (Articulos), $n^{\circ}$ 19, p. 3-25. ISSN: 1578-5157 http://dx.doi.org/10.21138/GF.458

Evolución de la superficie ocupada por árboles pioneros en los distintos estratos altitudinales

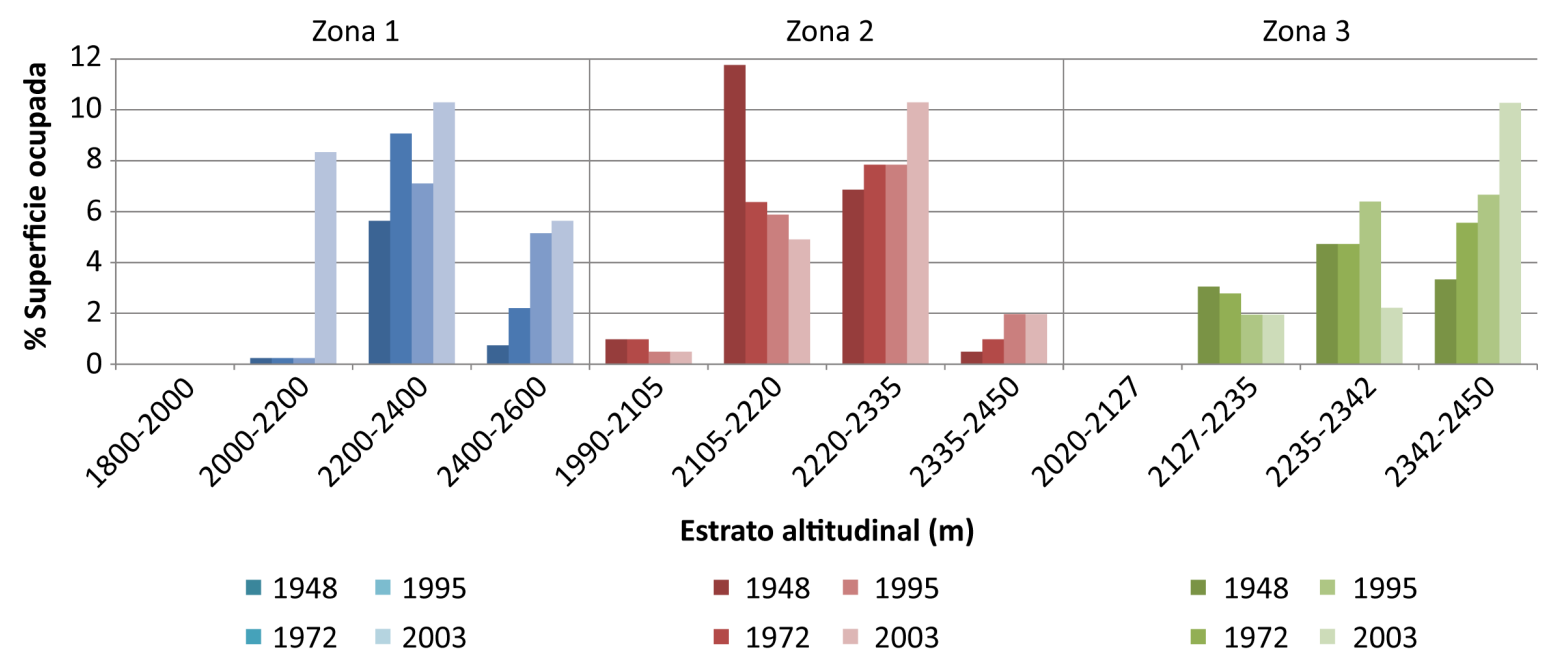

Figura 9. Evolución de la superficie ocupada por árboles pioneros a lo largo de la se rie temporal en las tres zonas de estudio según los dis tintos estratos altitudinales.

En cuanto a la posición altitudinal de los árboles pioneros (figura 10) se ha podido observar que en la zona 1 es donde observamos un mayor incremento altitudinal $(94 \mathrm{~m})$, llegando a cotas máximas de $2.563 \mathrm{~m}$, mientras que en la zona 2 y la zona 3 suben $52 \mathrm{~m}$ y $26 \mathrm{~m}$, hasta cotas de 2.407 m y 2.444 m, respectivamente, y prácticamente entre el 1995 y el 2003.

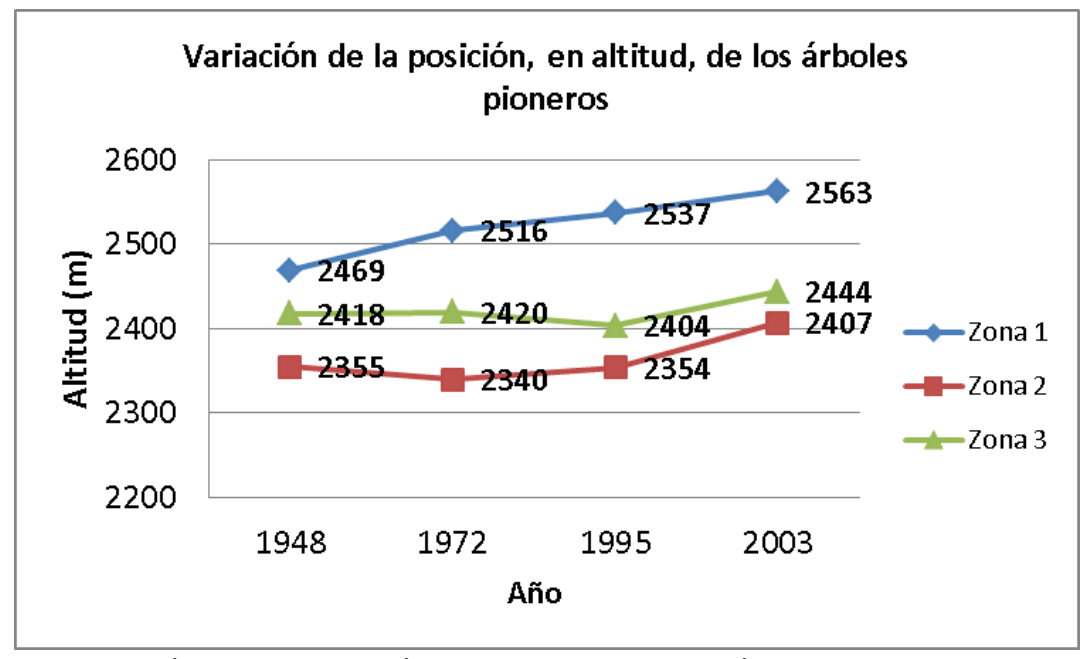

Figura 10. Variación de la posición, en altitud, de los árboles pione ros a lo largo del periodo de estudio.

Los resultados obtenidos coinciden con los de otros autores que han realizado trabajos en zonas similares de los Pirineos y que han detectado que en la gran mayoría de los emplazamientos 
González-Guerrero, O., Cruañas Cruells, G., Ninyerola Casals, M. (2017): “Análisis de la dinámica espacio-temporal (1948-2003) del limite altitudinal del bosque (tree line) en Andorra mediante fotografia aérea”, GeoFocus (Articulos), $n^{\circ}$ 19, p. 3-25. ISSN: 1578-5157 http://dx.doi.org/10.21138/GF.458

estudiados se detectan expansiones del área boscosa (Batllori y Gutiérrez, 2008; Améztegui et al., 2016).

\subsection{Cambios en el trazado de la tree line}

Mediante un segundo proceso de fotointerpretación más detallado y basado en el anterior (ver apartado 3.3 para detalles) se estudia el trazado de la tree line. La figura 11 permite observar claras diferencias sobre el terreno entre 1948 y 2003. Además, estos cambios se han analizado en relación a la altitud (figura 12).

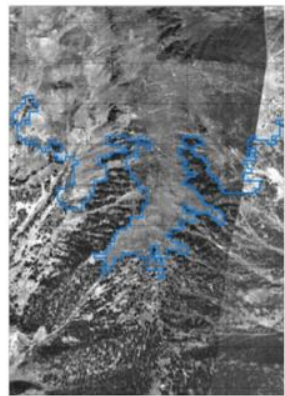

Zona 1: 1948

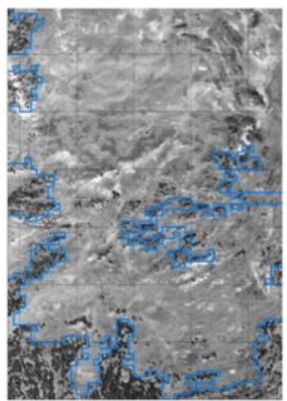

Zona 2: 1948

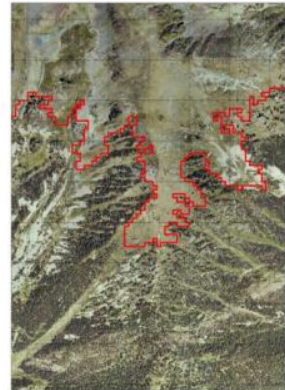

Zona 1: 2003

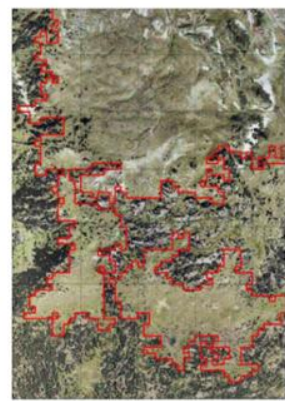

Zona 2: 2003

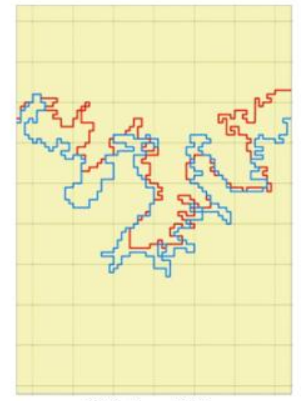

$100 \lcm{0} \quad 300 \mathrm{~m}$

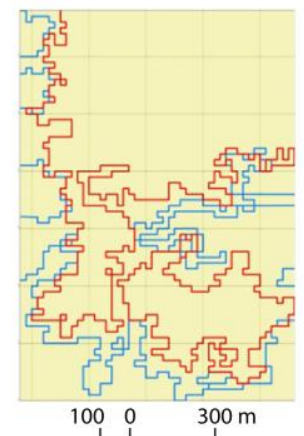

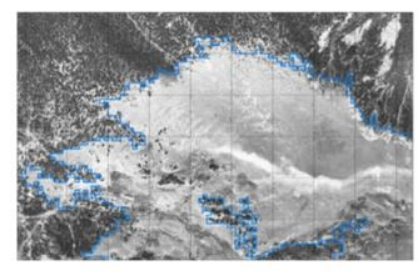

Zona 3: 1948

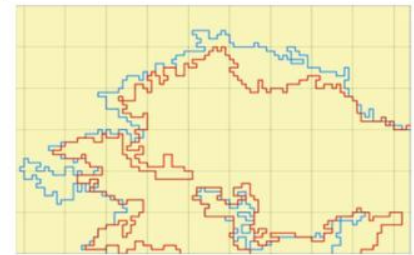

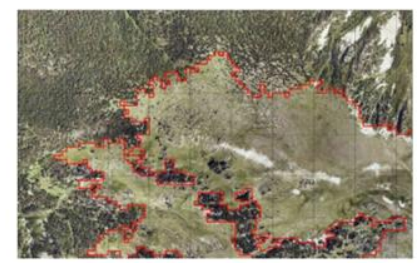

Zona 3: 2003

$1000300 \mathrm{~m}$

_ Tree line 1948

_ Tree line 2003

Figura 11. Evolución de la tree line entre 1948 y 2003 en las tres zonas de estudio 
González-Guerrero, O., Cruañas Cruells, G., Ninyerola Casals, M. (2017): “Análisis de la dinámica espacio-temporal (1948-2003) del límite altitudinal del bosque (tree line) en Andorra mediante fotografia aérea”, GeoFocus (Artículos), $n^{\circ}$ 19, p. 3-25. ISSN: 1578-5157 http://dx.doi.org/10.21138/GF.458

Los resultados obtenidos permiten comprobar como en la zona 1 la altitud media de la tree line ha aumentado en 30 m entre 1948 y 2003, aunque la cota del punto más alto y más bajo ha disminuido en $1 \mathrm{~m}$ y $9 \mathrm{~m}$ respectivamente. Recordemos que el error de georeferenciación de las imágenes es de, aproximadamente, $9 \mathrm{~m}$. Las tree line de las zonas 2 y 3 presentan menos variación en altitud durante este periodo. La altitud media en estos casos ha aumentado en $20 \mathrm{~m}$ y $17 \mathrm{~m}$ respectivamente. En este caso, cabe destacar que la zona 3 es la que experimenta cambios más importantes en la altitud de los puntos más alto y más bajo entre 1948 y 2003, variando 37 m y 87 $\mathrm{m}$ respectivamente. La tree line de la zona 2 es, pues, la zona que menos cambios altitudinales presenta.

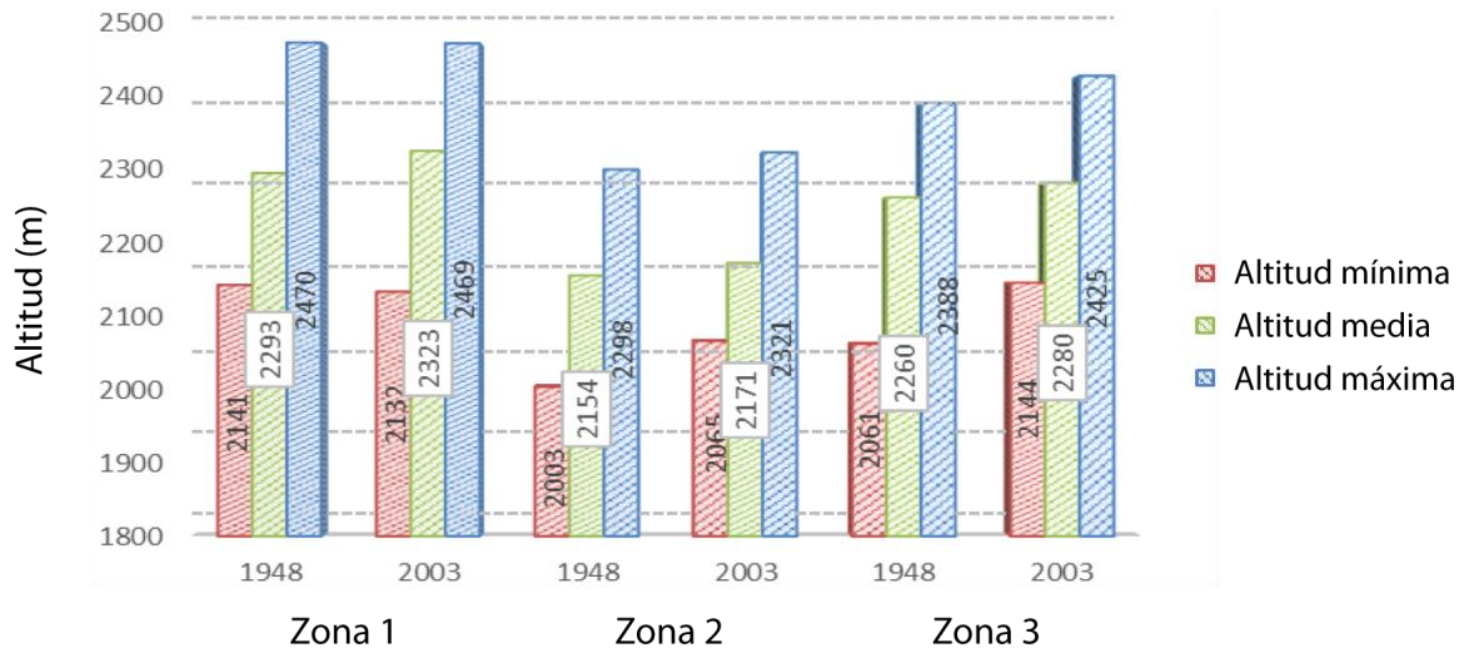

Año y zona

Figura 12. Variaciones en la altitud en la cual se sitúa la tree line en los años 1948 y 2003 en las tres zonas de estudio.

También se ha estimado el grado de coincidencia de las tree line de 1948 y 2003 en cada una de las zonas. Así, se ha comprobado que en la zona 2 es donde la tree line de 2003 tiene menos grado de coincidencia con la de $1948(13,86 \%)$, mientras que en la zona 1 y en la zona 3 tienen coincidencias del orden de 18,18 \% y 28,71 \% respectivamente. Por tanto, la zona 2 es la que más cambios presenta, tanto respecto al recubrimiento arbóreo como en el grado de coincidencia de las tree line aunque, por el contrario, es la zona donde menos variaciones de altitud se han producido.

Finalmente, se ha estimado la velocidad de crecimiento del bosque en su conjunto durante estos 55 años. Es decir, el aumento total de hectáreas con diferentes grados de ocupación arbórea (recubrimientos de $\leq 10$ a $50 \%$, incluyendo, por tanto, a los árboles pioneros) que presenta el bosque desde 1948 hasta el 2003. Los resultados obtenidos (figura 13) permiten ver como el bosque de la zona 1 muestra el crecimiento medio en el tiempo más alto, con valores de 0,95 ha/año. La zona 2 y la zona 3 tienen crecimientos menores, concretamente de 0,46 y 0,76 ha/año respectivamente. 
González-Guerrero, O., Cruañas Cruells, G., Ninyerola Casals, M. (2017): “Análisis de la dinámica espacio-temporal (1948-2003) del límite altitudinal del bosque (tree line) en Andorra mediante fotografia aérea”, GeoFocus (Artículos), $n^{\circ}$ 19, p. 3-25. ISSN: 1578-5157 http://dx.doi.org/10.21138/GF.458

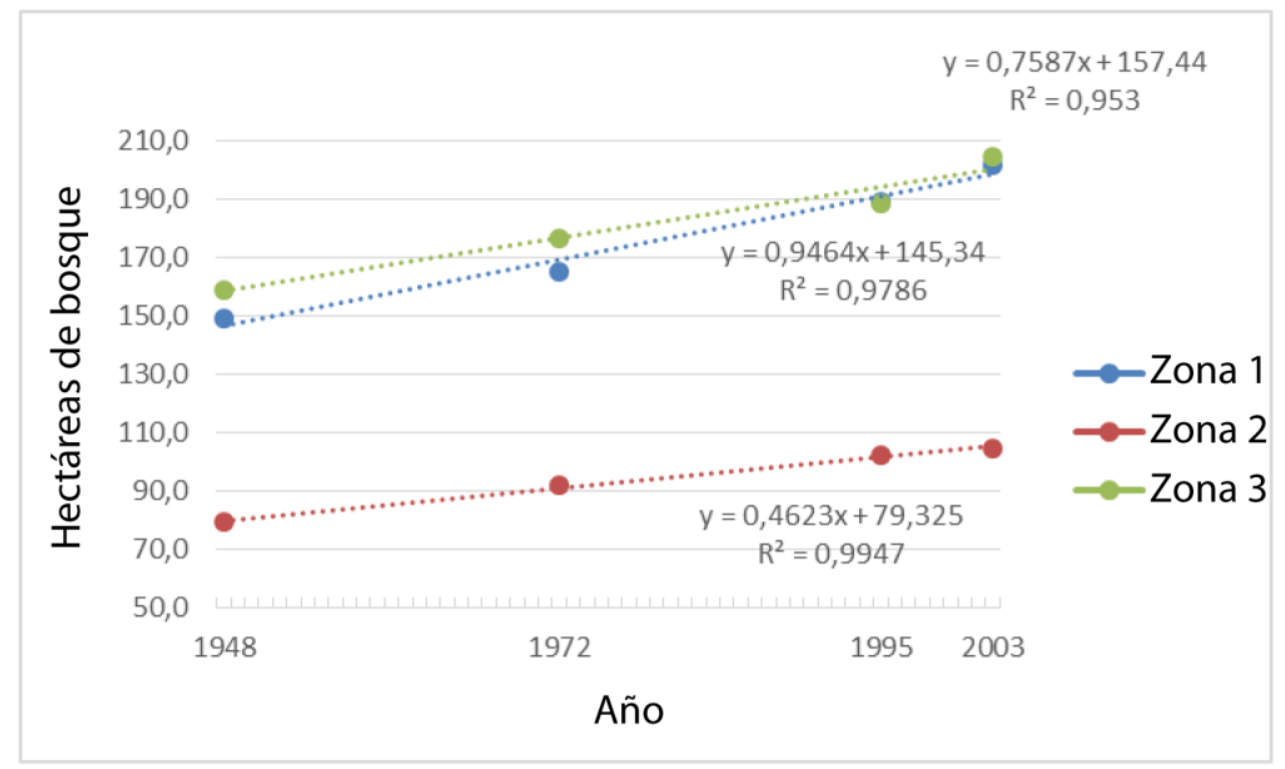

\section{Figura 13. Variación global de la supe rficie ocupada por el bosque en las dife rentes zonas de estudio}

\section{Conclusiones}

A la luz de los detallados resultados, se puede concluir que la metodología aplicada para la fotointerpretación de la tree line ha permitido cuantificar tanto los cambios en el recubrimiento de los bosques como los cambios en altitud de los árboles que se encuentran en el límite superior del bosque.

Aun así, los valores de desplazamientos absolutos deben leerse teniendo en cuenta que su cuantificación se ve afectada por la incertidumbre planimétrica derivada de los errores propios en la georreferenciación de las imágenes, por lo que se ha tratado de minimizar dicho error fotointerpretando a una escala de menor detalle al ofrecido por las imágenes originales (tal y como se explica en los apartados 3.1 y 3.3 ).

Respecto al recubrimiento arbóreo, se deduce que las tres zonas de estudio se encuentran en fase de desarrollo. La superficie considerada como bosque ha ido en aumento desde 1948 hasta 2003 en las distintas zonas estudiadas con escasas excepciones.

También cabe destacar que el análisis de las imágenes ha permitido cuantificar la densificación del bosque a lo largo de la serie temporal, sobre todo en los estratos altitudinales más bajos. Aunque en este trabajo no se han abordado cuestiones relacionadas con la gestión del bosque y su explotación, esta constatación es importante ya que la densificación del bosque en sus zonas más cercanas a la tree line es uno de los indicadores (junto con las variaciones del límite altitudinal del bosque y el grado de desarrollo de los árboles) utilizados en estudios que relacionan estos signos 
González-Guerrero, O., Cruañas Cruells, G., Ninyerola Casals, M. (2017): “Análisis de la dinámica espacio-temporal (1948-2003) del límite altitudinal del bosque (tree line) en Andorra mediante fotografia aérea”, GeoFocus (Artículos), $n^{\circ}$ 19, p. 3-25. ISSN: 1578-5157 http://dx.doi.org/10.21138/GF.458

con el cambio climático (Danby \& Hik, 2007). En este sentido, la metodología aplicada parece adecuada para trabajos futuros que apunten en esta dirección.

A partir de la superfic ie ocupada por el conjunto del bosque y su evolución, se ha estimado también la velocidad media de crecimiento global, siendo la zona 1 (parroquia de Ordino-Massana) la que presenta una velocidad mayor, del orden de 0,95 ha/año, mientras que la zona 2 y la zona 3 presentan velocidades sensiblemente menores, de 0,46 y 0,76 ha/año respectivamente.

Finalmente, indicar que la zona 3 (parroquia de Escaldes-Engordany) es la única en que la cota máxima y mínima de la tree line experimentan descensos en el tiempo aunque, en cambio, la velocidad de crecimiento global del bosque es positiva y superior en hectáreas a la de la zona 2.

Aunque la metodología aplicada ha permitido detectar claramente los cambios acontecidos en las distintas zonas seleccionadas, se requeriría un estudio con un mayor número de muestras y con datos climáticos detallados (Ninyerola et al., 2007), que permitieran buscar una posible relación entre los resultados obtenidos mediante fotointerpretación con los cambios en el clima de la zona. En este sentido, podrían plantearse mejoras en la selección de las zonas de estudio, aplicando variables como la temperatura o la evapotranspiración.

En trabajos futuros, deberían tenerse en cuenta, igualmente, los cambios sucedidos en el tiempo en cuanto a la gestión del territorio y, sobretodo, de los bosques por parte del Gobierno de Andorra. Siendo Andorra un país con tradición en la explotación de los bosques, la práctica de ganadería de montaña y también conocido por la práctica de deportes de invierno muy ligados a la montaña, podemos esperar una importante presencia humana que claramente debemos tener en cuenta para valorar las causas de los cambios detectados en la evolución de los bosques de alta montaña.

\section{Agradecimientos}

Este trabajo ha sido parcialmente financiado por el Generalitat de Catalunya (GRUMETSgrupo de investigación consolidado, de calidad y financiado desde 2009. SGR 2014 núm. 1491 y SGR 2009 núm. 1511), el Ministerio de Economía y Competitividad y el Fondo Europeo de Desarrollo Regional (ERDF) bajo los proyectos CGL2012-33927 (DinaCliVe) y CGL2015-69888-P (ACAPI). Los autores agradecen al CENMA y, en especial, a Roger Caritg, la cesión de las imágenes aéreas de los distintos vuelos fotográmetricos para la realización de este trabajo.

\section{Referencias bibliográficas}

Améztegui, A., Brotons, LL., Coll, LL. (2010): "Land-use changes as major drivers of mountain pine (Pinus uncinata Ram.) expansion in the Pyrenees", Global Ecology and Biogeography, 19, pp. 632-641.

Améztegui, A., Coll, L.L., Brotons, L.L., Ninot, J.M. (2016): "Land-use legacies rather than climate change are driving the recent upward shift of the mountain tree line in the Pyrenees", Global Ecology and Biogeography, 25(3), pp. 263-273. 
González-Guerrero, O., Cruañas Cruells, G., Ninyerola Casals, M. (2017): “Análisis de la dinámica espacio-temporal (1948-2003) del límite altitudinal del bosque (tree line) en Andorra mediante fotografia aérea”, GeoFocus (Artículos), $n^{\circ}$ 19, p. 3-25. ISSN: 1578-5157 http://dx.doi.org/10.21138/GF.458

Batllori, E., Gutiérrez, E. (2008): "Regional tree line dynamics in response to global change in the Pyrenees”, Journal of Ecology, 96(6), pp.1275-1288.

Blarquez, O., Carcaillet, C., Bremond, L., Mourier, B., Radakovitch, O. (2009): "Trees in the subalpine belt since 1,1700 cal. B.P.: origin, expansion and alteration of the modern forest", Holocene, 20, pp. 139-146.

Camarero, J.J., Garcia-Ruiz, J.M., Sangusa-Barreda, G., Galvan, J.D., Alla, A.Q., Sanjuan, Y, Begueria, S., Gutierrez, E. (2015): "Recent and intense dynamics in a formerly static Pyrenean treeline", Arctic Antarctic and Alpine Research, 47(4), pp. 773-783.

Carlson, B. Z., Renaud, J., Biron, P.E., Choler, P. (2014): "Long-term modeling of the forestgrassland ecotone in the French Alps: implications for land Management and conservation", Ecological Applications, 24(5), pp. 1213-1225.

Cunill, R., Soriano, J.M., Bal, M.C., Pelachs, A., Perez-Obiol, R. (2012): "Holocene treeline changes on the south slope of the Pyrenees: a pedoanthracological analys is", Vegetation History and Archaeobotany, 21(4-5), pp. 373-384.

Danby, R.K., Hik, D.S. (2007): "Evidence of recent treeline dynamics in southwest Yukon from aerial photographs", Artic, 60(4), pp. 411-420.

Didier, L. (2001): "Invasion patterns of European larch and Swiss stone pine in subalpine pastures in the French Alps". Forest Ecology and Management, 145, pp. 67-77.

Elliot G.P. (2012): "Extrinsic regime shifts drive abrupt changes in regeneration dynamics at upper treeline in the Rocky Mountains, USA”, Ecology, 93(7), pp. 1614-1625.

Gartzia, M., Alados, C.L., Pérez-Cabello, F. (2014): "Assessment of the effects of biophysical and anthropogenic factors on woody plant encroachment in dense and sparse mountain grasslands based on remote sensing data", Progress in Physical Geography, 38(2), pp. 201-217.

Gehrig-Fasel, J., Guisan, A., Zimmermann, N.E. (2007): "Tree line shifts in the Swiss Alps: Climate change or land abandonment?”, Journal of Vegetation Science, 18, pp. 571-582.

Gindl, W. (1999): "Climatic significance of light rings in timberline spruce, Picea abies, Austrian Alps", Arctic Antarctic and Alpine Research, 31(3), pp. 242-246.

Grace, J., Berninger, F., Nagy, L. (2002): "Impacts of climate change on the tree line", Annals of Botany, 90(4), pp. 537-544.

Harsch, M.A., Hulme, P.E., McGlone, M.S., Duncan, R.P. (2009): "Are treelines advancing? A global meta-analysis of treeline response to climate warming", Ecology Letters, 12 (10), pp. 10401049 .

Jacob, M., Frankl, A., Beeckman, H., Mesfin, G., Hendrickx, M., Guyassa, E., Nyssen, J. (2015): "North Ethiopian Afro-Alpine Tree Line Dynamics and Forest-Cover Change Since the Early 20th Century", Land Degradation and Development, 26 (7), pp. 654-664.

Keller, F., Kienast, F., Beniston, M. (2000): "Evidence of response of vegetation to environmental change on high-elevation sites in the Swiss Alps", Regional Environmental Change, 1, pp. 70-77.

Körner, C.H. (1998): “A re-assessment of high elevation treeline positions and their explanation”, Oecologia, 115, pp.445-459. 
González-Guerrero, O., Cruañas Cruells, G., Ninyerola Casals, M. (2017): “Análisis de la dinámica espacio-temporal (1948-2003) del límite altitudinal del bosque (tree line) en Andorra mediante fotografia aérea”, GeoFocus (Artículos), $n^{\circ}$ 19, p. 3-25. ISSN: 1578-5157 http://dx.doi.org/10.21138/GF.458

Körner, C. (2007): "Climatic treelines: Conventions, global patterns, causes", Erdkunde, 61 (4), pp. 316-324.

Kullman, L. (1998): "Tree-limits and montane forests in the Swedish Scandes: sensitive biomonitors of climate change and variability", Ambio, 27, pp. 312-321.

Kullman, L. (2001): "20th century climate warming and tree-limit rise in the southern Scandes of Sweden", Ambio, 30 (2), pp. 72-80.

Morueta-Holme, N., Engemann, K., Sandoval-Acuna, P., Jonas, J.D., Segnitz, R.M., Svenning, J.C. (2015): "Strong ups lope shifts in Chimborazo's vegetation over two centuries since Humboldt", Proceedings of the National Academy of Sciences of the United States of America, 112 (41), pp.12741-12745.

Motta, R., Nola, P. (2001): "Growth trends and dynamics in sub-alpine forest stands in the Varaita Valley (Piedmont, Italy) and the ir relationships with human activities and global change", Journal of Vegetation Science, 12(2), pp.219-230.

Motta, R., Morales, M., Nola, P. (2006): "Human land-use, forest dynamics and tree growth at the treeline in the Western Italian Alps", Annals of Forest Science, 63, pp. 739-747.

Ninyerola, M., Pons, X., Roure, J. M. (2007): "Objective air temperature mapping for the Iberian Peninsula using spatial interpolation and GIS", International Journal of Climatology, 27 (9), pp. 1231-1242.

Noble, I.R. (1993): "A model of the responses of ecotones to climate-change", Ecological Applications, 3 (3), pp. 396-403.

Paulsen, J., Weber, U.M., Körner, C. (2000): "Tree growth near tree line: Abrupt or gradual reduction w ith altitude?", Arctic Antarctic and Alpine Research, 32, pp. 14-20.

Paulsen, J., Körner, C. (2001): "GIS-analys is of tree-line elevation in the Swiss Alps suggests no exposure effect”, Journal of Vegetation Science, 12, pp. 817-824.

Rey F., Schwörer C., Gobet, E., Colombaroli, D., van Leeuwen, J.F.N., Schle iss, S., Tinner, W. (2013): "Climatic and human impacts on mountain vegetation at Lauenensee (Bernese Alps, Switzerland) during the last 14,000 years", Holocene, 23 (10), pp. 1415-1427.

Schworer, C., Kaltenrieder, P., Glur, L., Berlinger, M., Elbert, J., Frei, S., Gilli, A., Hafner, A., Anselmetti, F.S., Gros jean, M., Tinner, W. (2014): "Holocene climate, fire and vegetation dynamics at the treeline in the Northwestern Swiss Alps", Vegetation History and Archaeobotany, 23(5), pp. 479-496.

Stueve, K.M., Isaacs, R. E., Tyrrell, L.E., Densmore, R.V. (2011): "Spatial variability of biotic and abiotic tree establishment constraints across a treeline ecotone in the Alaska Range", Ecology, 92 (2), pp. 496-506.

Tinner, W., Theurillat, J. (2003): "Uppermost limit, extent, and fluctuations of the timberline and treeline ecocline in the Swiss Central Alps during the past 11,500 years", Arctic Antarctic and Alpine Research, 35, pp.158-169. 


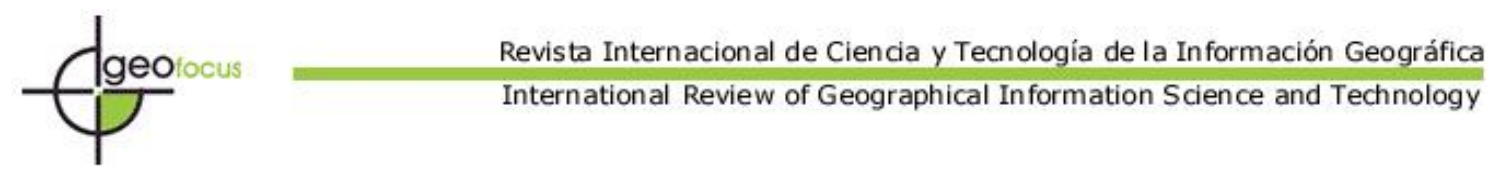

González-Guerrero, O., Cruañas Cruells, G., Ninyerola Casals, M. (2017): “Análisis de la dinámica espacio-temporal (1948-2003) del límite altitudinal del bosque (tree line) en Andorra mediante fotografia aérea”, GeoFocus (Artículos), $n^{\circ}$ 19, p. 3-25. ISSN: 1578-5157 http://dx.doi.org/10.21138/GF.458

Valsecchi, V., Tinner, W. (2010): "Vegetation responses to climàtic variability in the Swiss Southern Alps during the Misox event at the early-mid Holocene transition", Journal of Quaternary Science, 25(8), pp. 1248-1258.

Walther, G.R., Beissner, S., Burga, C.A. (2005): "Trends in the upward shift of alpine plants", Journal of Vegetation Science, 16(5), pp. 541-548.

Wick, L., van Leeuwen, J.F.N., van der Knaap, W.O., Lotter, A.F. (2003): "Holocene vegetation development in the catchment of Sagistalsee (1935 m asl), a small lake in the Swiss Alps", Journal of Paleolimnology, 30(3), pp. 261-272.

Zhang, Y.J, Xu, M., Adams, J., Wang, X.C. (2009): "Can Landsat imagery detect tree line dynamics?”, International Journal of Remote Sensing, 30 (5), pp. 1327-1340. 
González-Guerrero, O., Cruañas Cruells, G., Ninyerola Casals, M. (2017): “Análisis de la dinámica espacio-temporal (1948-2003) del límite altitudinal del bosque (tree line) en Andorra mediante fotografia aérea”, GeoFocus (Artículos), $n^{\circ}$ 19, p. 3-25. ISSN: 1578-5157 http://dx.doi.org/10.21138/GF.458

\section{APÉNDICE 1}

A) Superfic ie según el grado de recubrimiento arbóreo de la zona 1 en los distintos rangos de altitud para las cuatro fechas consideradas.

\begin{tabular}{|c|c|c|c|c|c|c|c|c|c|c|c|}
\hline \multicolumn{12}{|c|}{ Superficie en ha según el grado de recubrimiento. Zona 1} \\
\hline Año & Altitud & $0 \%$ & $<10 \%$ & $10 \%$ & $20 \%$ & $30 \%$ & $40 \%$ & $50 \%$ & $\begin{array}{c}\text { Suma } \\
10-50 \%\end{array}$ & $\leq 20 \%$ & $\geq 30 \%$ \\
\hline \multirow{4}{*}{1948} & $1800-2000$ & 0,0 & 0,0 & 6,0 & 6,0 & 3,6 & 6,6 & 2,4 & 24,6 & 12,0 & 12,6 \\
\hline & $2000-2200$ & 1,8 & 0,6 & 23,4 & 15,0 & 20,4 & 12,6 & 5,4 & 76,8 & 39,0 & 38,4 \\
\hline & $2200-2400$ & 33,0 & 13,8 & 28,8 & 10,2 & 6,6 & 0,0 & 0,0 & 45,6 & 52,8 & 6,6 \\
\hline & $2400-2600$ & 45,0 & 1,8 & 1,2 & 0,6 & 0,0 & 0,0 & 0,0 & 1,8 & 3,6 & 0,0 \\
\hline \multirow{4}{*}{1972} & $1800-2000$ & 0,0 & 0,0 & 4,8 & 3,6 & 4,8 & 6,6 & 4,8 & 24,6 & 8,4 & 16,2 \\
\hline & \begin{tabular}{|l|l|}
$2000-2200$ \\
\end{tabular} & 0,6 & 0,6 & 19,8 & 13,8 & 23,4 & 15,0 & 6,0 & 78,0 & 34,2 & 44,4 \\
\hline & $2200-2400$ & 18,6 & 22,2 & 30,0 & 11,4 & 10,2 & 0,0 & 0,0 & 51,6 & 63,6 & 10,2 \\
\hline & $2400-2600$ & 41,4 & 5,4 & 1,2 & 0,6 & 0,0 & 0,0 & 0,0 & 1,8 & 7,2 & 0,0 \\
\hline \multirow{4}{*}{1995} & 1800-2000 & 0,0 & 0,0 & 0,6 & 4,8 & 4,8 & 6,0 & 8,4 & 24,6 & 5,4 & 19,2 \\
\hline & \begin{tabular}{|l|l}
$2000-2200$ \\
\end{tabular} & 0,6 & 0,6 & 15,0 & 13,8 & 25,2 & 15,6 & 8,4 & 78,0 & 29,4 & 49,2 \\
\hline & 2200-2400 & 20,4 & 17,4 & 31,8 & 9,0 & 12,6 & 0,6 & 0,6 & 54,6 & 58,2 & 13,8 \\
\hline & $2400-2600$ & 34,2 & 12,6 & 0,0 & 1,8 & 0,0 & 0,0 & 0,0 & 1,8 & 14,4 & 0,0 \\
\hline \multirow{4}{*}{2003} & $1800-2000$ & 0,0 & 0,0 & 1,8 & 4,8 & 4,8 & $\overline{5,4}$ & 7,8 & 24,6 & $\overline{6,6}$ & 18,0 \\
\hline & 2000-2200 & 0,6 & 20,4 & 12,6 & 19,8 & 13,8 & 11,4 & 0,6 & 58,2 & 52,8 & 25,8 \\
\hline & $2200-2400$ & 10,2 & 25,2 & 33,6 & 12,6 & 9,6 & 0,6 & 0,6 & 57,0 & 71,4 & 10,8 \\
\hline & $2400-2600$ & 32,4 & 13,8 & 0,6 & 1,8 & 0,0 & 0,0 & 0,0 & 2,4 & 16,2 & 0,0 \\
\hline
\end{tabular}


González-Guerrero, O., Cruañas Cruells, G., Ninyerola Casals, M. (2017): “Análisis de la dinámica espacio-temporal (1948-2003) del limite altitudinal del bosque (tree line) en Andorra mediante fotografia aérea”, GeoFocus (Articulos), $n^{\circ}$ 19, p. 3-25. ISSN: 1578-5157 http://dx.doi.org/10.21138/GF.458

B) Superficie según el grado de recubrimiento arbóreo de la zona 2 en los distintos rangos de altitud para las cuatro fechas consideradas.

\begin{tabular}{|c|c|c|c|c|c|c|c|c|c|c|c|}
\hline \multicolumn{12}{|c|}{ Superficie en ha según el grado de recubrimiento. Zona 2} \\
\hline Año & Altitud & $0 \%$ & $<10 \%$ & $10 \%$ & $20 \%$ & $30 \%$ & $40 \%$ & $50 \%$ & $\begin{array}{c}\text { Suma } \\
10-50 \%\end{array}$ & $\leq 20 \%$ & $\geq 30 \%$ \\
\hline \multirow{4}{*}{1948} & $1990-2105$ & 0,6 & 1,2 & 9,0 & 4,8 & 4,2 & 3,6 & 0,0 & 21,6 & 15,0 & 7,8 \\
\hline & $2105-2220$ & 11,4 & 14,4 & 14,4 & 5,4 & 1,8 & 0,6 & 0,0 & 22,2 & 34,2 & 2,4 \\
\hline & $2220-2335$ & 18,0 & 8,4 & 7,2 & 1,2 & 1,8 & 0,6 & 0,0 & 10,8 & 16,8 & 2,4 \\
\hline & $2335-2450$ & 13,2 & 0,6 & 0,0 & 0,0 & 0,0 & 0,0 & 0,0 & 0,0 & 0,6 & 0,0 \\
\hline \multirow{4}{*}{1972} & $1990-2105$ & 0,0 & 1,2 & 5,4 & 5,4 & 6,0 & 3,6 & 1,8 & 22,2 & 12,0 & 11,4 \\
\hline & $2105-2220$ & 7,2 & 7,8 & 15,0 & 10,8 & 4,8 & 2,4 & 0,6 & 33,6 & 33,6 & 7,8 \\
\hline & $2220-2335$ & 10,8 & 9,6 & 8,4 & 6,0 & 1,2 & 0,6 & 0,0 & 16,2 & 24,0 & 1,8 \\
\hline & $2335-2450$ & 12,6 & 1,2 & 0,0 & 0,0 & 0,0 & 0,0 & 0,0 & 0,0 & 1,2 & 0,0 \\
\hline \multirow{4}{*}{1995} & $1990-2105$ & 0,0 & 0,6 & 3,6 & 7,2 & 4,2 & 7,8 & 0,0 & 22,8 & 11,4 & 12,0 \\
\hline & $2105-2220$ & 1,2 & 7,2 & 13,8 & 11,4 & 7,8 & 4,2 & 3,0 & 40,2 & 32,4 & 15,0 \\
\hline & $2220-2335$ & 8,4 & 9,6 & 10,2 & 5,4 & 2,4 & 0,6 & 0,0 & 18,6 & 25,2 & 3,0 \\
\hline & $2335-2450$ & 10,8 & 2,4 & 0,6 & 0,0 & 0,0 & 0,0 & 0,0 & 0,6 & 3,0 & 0,0 \\
\hline \multirow{4}{*}{2003} & 1990-2105 & 0,0 & 0,6 & 3,0 & 6,6 & 5,4 & 7,8 & 0,0 & 22,8 & 10,2 & 13,2 \\
\hline & $2105-2220$ & 1,2 & 6,0 & 14,4 & 11,4 & 8,4 & 3,6 & 3,6 & 41,4 & 31,8 & 15,6 \\
\hline & $2220-2335$ & 6,0 & 12,6 & 9,6 & 5,4 & 2,4 & 0,6 & 0,0 & 18,0 & 27,6 & 3,0 \\
\hline & $2335-2450$ & 10,8 & 2,4 & 0,6 & 0,0 & 0,0 & 0,0 & 0,0 & $\overline{0,6}$ & 3,0 & $\overline{0,0}$ \\
\hline
\end{tabular}


González-Guerrero, O., Cruañas Cruells, G., Ninyerola Casals, M. (2017): “Análisis de la dinámica espacio-temporal (1948-2003) del limite altitudinal del bosque (tree line) en Andorra mediante fotografia aérea”, GeoFocus (Articulos), $n^{\circ}$ 19, p. 3-25. ISSN: 1578-5157 http://dx.doi.org/10.21138/GF.458

C) Superficie según el grado de recubrimiento arbóreo de la zona 3 en los distintos rangos de altitud para las cuatro fechas consideradas.

\begin{tabular}{|c|c|c|c|c|c|c|c|c|c|c|c|}
\hline \multicolumn{12}{|c|}{ Superficie en ha según el grado de recubrimie nto. Zona 3} \\
\hline Año & Altitud & $0 \%$ & $<\mathbf{1 0} \%$ & $10 \%$ & $20 \%$ & $30 \%$ & $40 \%$ & $50 \%$ & $\begin{array}{c}\text { Suma } \\
\mathbf{1 0 - 5 0 \%}\end{array}$ & $\leq \mathbf{2 0} \%$ & $\geq 30 \%$ \\
\hline \multirow{4}{*}{1948} & $2020-2127$ & 0,0 & 0,0 & 6,0 & 2,4 & 3,6 & 0,6 & 1,2 & 13,8 & 8,4 & 5,4 \\
\hline & $2127-2235$ & 4,8 & 6,6 & 9,0 & 10,8 & 8,4 & 10,2 & 13,8 & 52,2 & 26,4 & 32,4 \\
\hline & 2235-2342 & 13,8 & 10,2 & 10,8 & 13,2 & 12,6 & 12,6 & 6,6 & 55,8 & 34,2 & 31,8 \\
\hline & $2342-2450$ & 38,4 & 7,2 & 12,0 & 0,6 & 0,6 & 0,0 & 0,0 & 13,2 & 19,8 & 0,6 \\
\hline \multirow{4}{*}{1972} & $2020-2127$ & 0,0 & 0,0 & 3,0 & 4,2 & 1,8 & 3,0 & 1,8 & 13,8 & 7,2 & 6,6 \\
\hline & $2127-2235$ & 3,6 & 6,0 & 6,0 & 13,2 & 9,0 & 10,2 & 15,6 & 54,0 & 25,2 & 34,8 \\
\hline & $2235-2342$ & 7,8 & 10,2 & 14,4 & 11,4 & 12,6 & 10,2 & 13,2 & 61,8 & 36,0 & 36,0 \\
\hline & $2342-2450$ & 28,2 & 12,0 & 11,4 & 6,0 & 1,2 & 0,0 & 0,0 & 18,6 & 29,4 & 1,2 \\
\hline \multirow{4}{*}{1995} & $2020-2127$ & 0,0 & 0,0 & 2,4 & 1,8 & 3,6 & 3,6 & 2,4 & 13,8 & 4,2 & 9,6 \\
\hline & $2127-2235$ & 4,2 & 4,2 & 6,6 & 13,2 & 7,2 & 8,4 & 19,8 & 55,2 & 24,0 & 35,4 \\
\hline & $2235-2342$ & 0,0 & 13,8 & 13,8 & 10,8 & 14,4 & 13,2 & 13,8 & 66,0 & 38,4 & 41,4 \\
\hline & $2342-2450$ & 23,4 & 14,4 & 9,0 & 9,0 & 3,0 & 0,0 & 0,0 & 21,0 & 32,4 & 3,0 \\
\hline \multirow{4}{*}{2003} & $2020-2127$ & 0,0 & 0,0 & 1,8 & 2,4 & 3,6 & 3,6 & 2,4 & 13,8 & 4,2 & 9,6 \\
\hline & 2127-2235 & 4,2 & 4,2 & 6,6 & 12,6 & 7,8 & 8,4 & 19,8 & 55,2 & 23,4 & 36,0 \\
\hline & $2235-2342$ & 0,0 & 4,8 & 20,4 & 13,2 & 13,8 & 13,8 & 13,8 & 75,0 & 38,4 & 41,4 \\
\hline & $2342-2450$ & 7,2 & 22,2 & 15,0 & 9,6 & 4,8 & 0,0 & 0,0 & 29,4 & 46,8 & 4,8 \\
\hline
\end{tabular}


